\title{
Epidemiology of maxillofacial trauma in the elderly: a European
} multicenter study

\section{Brucoli, Matteo}

2020-09

Brucoli , M , Boffano , P , Romeo , I, Corio , C , Benech , A, Ruslin , M , Forouzanfar , T , pÿJensen, T S, Rodríguez-Santamarta , T , de Vicente , J C , Snäll , J , Thorén , H, Anii , B , Konstantinovic , V S, Pechalova , P , Pavlov , N , Daskalov , H, Doykova , I, Kelemith , K, Tamme , T , Kopchak , A, Shumynskyi , I , Corre , P , Bertin , H, Goguet , Q, Anquetil , M , pÿLouvrier , A , Meyer , C , Dovaak , T , Vozli , D , Birk , A, Tarle , M \& Dediol , E 2020 , ' Epidemiology of maxillofacial trauma in the elderly: a European multicenter study ' , Journal of stomatology, oral \& maxillofacial surgery, vol. 121 , no. 4 , pp. 330-338 . https://doi.org/10.1016/j.jormas.2019.09.

http://hdl.handle.net/10138/319501

https://doi.org/10.1016/j.jormas.2019.09.002

cc_by_nc_nd

acceptedVersion

Downloaded from Helda, University of Helsinki institutional repository.

This is an electronic reprint of the original article.

This reprint may differ from the original in pagination and typographic detail.

Please cite the original version. 


\section{Journal Pre-proof}

Epidemiology of maxillofacial trauma in the elderly: a European multicenter study

Matteo Brucoli MD DDS Paolo Boffano MD Irene Romeo MD Chiara Corio MD Arnaldo Benech MD DDS Muhammad Ruslin MD DDS PhD Tymour Forouzanfar MD DDS PhD Thomas Starch- Jensen MD PhD Tanía Rodríguez-Santamarta MD DDS Juan Carlos de Vicente MD DDS PhD Johanna Snäll MD DDS PhD Hanna Thorén MD DDS PhD Boban Aničić MD DDS Vitomir S. Konstantinovic DDS MD MSc PhD Petia Pechalova MD DDS PhD Nikolai Pavlov MD DDS Hristo Daskalov MD DDS Iva Doykova MD DDS Kadri Kelemith DDS Tiia Tamme MD PhD Andrey Kopchak MD DDS PhD levgen Shumynskyi MD DDS Pierre Corre MD PhD Helios Bertin MD PhD Quentin Goguet MD Marine Anquetil MD Aurélien Louvrier MD Christophe Meyer MD PhD Tadej Dovšak MD PhD David Vozlič MD Anže Birk MD Marko Tarle MD Emil Dediol MD PhD

PII: S2468-7855(19)30215-0

DOI: https://doi.org/doi:10.1016/j.jormas.2019.09.002

Reference:

JORMAS 745

To appear in: Journal of Stomatology oral and Maxillofacial Surgery

Received Date: 7 August 2019

Accepted Date: $\quad 4$ September 2019

Please cite this article as: Brucoli M, Boffano P, Romeo I, Corio C, Benech A, Ruslin M, Forouzanfar T, Jensen TS-, Rodríguez-Santamarta T, de Vicente JC, Snäll J, Thorén H, Aničić B, Konstantinovic VS, Pechalova P, Pavlov N, Daskalov H, Doykova I, Kelemith K, Tamme T, Kopchak A, Shumynskyi I, Corre P, Bertin H, Goguet Q, Anquetil M, Louvrier A, Meyer C, Dovšak T, Vozlič D, Birk A, Tarle M, Dediol E, Epidemiology of maxillofacial trauma in the elderly: a European multicenter study, Journal of Stomatology oral and Maxillofacial Surgery (2019), doi: https://doi.org/10.1016/j.jormas.2019.09.002 
This is a PDF file of an article that has undergone enhancements after acceptance, such as the addition of a cover page and metadata, and formatting for readability, but it is not yet the definitive version of record. This version will undergo additional copyediting, typesetting and review before it is published in its final form, but we are providing this version to give early visibility of the article. Please note that, during the production process, errors may be discovered which could affect the content, and all legal disclaimers that apply to the journal pertain.

(C) 2019 Published by Elsevier. 
Epidemiology of maxillofacial trauma in the elderly: a European multicenter study.

Matteo Brucoli MD DDS, ${ }^{1}$ Paolo Boffano MD, ${ }^{1}$ Irene Romeo MD, ${ }^{1}$ Chiara Corio MD, ${ }^{1}$ Arnaldo

Benech MD DDS, ${ }^{1}$ Muhammad Ruslin MD DDS PhD, ${ }^{2}$ Tymour Forouzanfar MD DDS PhD, ${ }^{3}$ Thomas

Starch- Jensen MD PhD, ${ }^{4}$ Tanía Rodríguez-Santamarta MD DDS, ${ }^{5}$ Juan Carlos de Vicente MD DDS PhD, ${ }^{5}$ Johanna Snäll MD DDS PhD, ${ }^{6}$ Hanna Thorén MD DDS PhD, ${ }^{7,8}$ Boban Aničić MD DDS, ${ }^{9}$ Vitomir

S. Konstantinovic DDS MD MSc PhD, ${ }^{9}$ Petia Pechalova MD DDS PhD, ${ }^{10}$ Nikolai Pavlov MD DDS, ${ }^{11}$ Hristo Daskalov MD DDS, ${ }^{10}$ Iva Doykova MD DDS, ${ }^{12}$ Kadri Kelemith DDS, ${ }^{13}$ Tiia Tamme MD PhD, ${ }^{14}$ Andrey Kopchak MD DDS PhD, ${ }^{15}$ levgen Shumynskyi MD DDS, ${ }^{16}$ Pierre Corre MD PhD, ${ }^{17}$ Helios Bertin MD PhD, ${ }^{17}$ Quentin Goguet MD, ${ }^{17}$ Marine Anquetil MD, ${ }^{17}$ Aurélien Louvrier MD, ${ }^{18,19}$ Christophe Meyer MD PhD, ${ }^{18,19}$ Tadej Dovšak MD PhD, ${ }^{20}$ David Vozlič MD, ${ }^{20}$ Anže Birk MD, ${ }^{20}$ Marko Tarle MD, ${ }^{21}$ Emil Dediol MD PhD. ${ }^{21}$

${ }^{1}$ Division of Maxillofacial Surgery, University Hospital “Maggiore della Carità", University of Eastern Piedmont, Novara, Italy

${ }^{2}$ Department of Oral and Maxillofacial Surgery, Hasanuddin University, Makassar, Indonesia

${ }^{3}$ Department of Oral and Maxillofacial Surgery/Oral Pathology, VU University Medical Center, Amsterdam, The Netherlands

${ }^{4}$ Department of Oral and Maxillofacial Surgery, Aalborg University Hospital, Aalborg, Denmark

${ }^{5}$ Servicio de Cirugía Maxilofacial, Hospital Universitario Central de Asturias, Oviedo, Spain

${ }^{6}$ Department of Oral and Maxillofacial Diseases, University of Helsinki and Helsinki University Hospital, Helsinki, Finland.

${ }^{7}$ Department of Oral and Maxillofacial Surgery, Institute of Dentistry, University of Turku.

${ }^{8}$ Department of Oral and Maxillofacial Diseases, Turku University Hospital, Turku, Finland

${ }^{9}$ Department of Maxillofacial surgery, School of Dental Medicine, University of Belgrade, Serbia

${ }^{10}$ Department of Oral surgery, Faculty of Dental Medicine, Medical University, Plovdiv, Bulgaria

11 Private practice of oral surgery, Plovdiv, Bulgaria

12 Department of maxillofacial surgery, Faculty of Dental Medicine, Medical University, Plovdiv, Bulgaria

${ }^{13}$ Department of maxillo-facial surgery, North Estonia Medical Centre Foundation, Tallinn, Estonia.

${ }^{14}$ Faculty of Medicine, University of Tartu, Tartu, Estonia

${ }^{15}$ Bogomolets National Medical University, Stomatological medical center, Kyiv, Ukraine.

${ }^{16}$ Bogomolets National Medical University, Kyiv City Clinical Emergency Hospital, Kyiv, Ukraine

${ }^{17}$ Division of Maxillofacial Surgery, Chu de Nantes, Nantes, France 
${ }^{18}$ Department of Oral and Maxillofacial Surgery - Hospital Dentistry Unit, University Hospital of Besançon - France

${ }^{19}$ University of Bourgogne - Franche-Comté, EA 4662 Nanomedicine Lab Imagery and Therapeutics, F-25000 Besançon - France

${ }^{20}$ Department of Maxillofacial and Oral Surgery of the University Medical Centre, Ljubljana, Slovenia

${ }^{21}$ Department of Maxillofacial Surgery, University Hospital Dubrava, Zagreb, Croatia Address correspondence and reprint requests to Dr Paolo Boffano: Division of Maxillofacial Surgery, University Hospital “Maggiore della Carità", University of Eastern Piedmont, Novara, Italy E-mail address: paolo.boffano@gmail.com

Disclosure: The authors have no financial interest to declare in relation to the content of this article. No funding

ABSTRACT:

Introduction: The progressive aging of European population seems to determine a change in the epidemiology, incidence and etiology of maxillofacial fractures with an increase in the frequency of old patients sustaining craniofacial trauma. The objective of the present study was to assess the demographic variables, causes, and patterns of facial fractures in elderly population (with 70 years or more).

Materials and Methods: The data from all geriatric patients (70 years or more) with facial fractures between January 1, 2013, and December 31, 2017, were collected. The following data were recorded for each patient: gender, age, voluptuary habits, comorbidities, etiology, site of facial fractures, synchronous body injuries, Facial Injury Severity Score (FISS).

Results: A total of 1334 patients (599 male and 735 female patients) were included in the study. Mean age was 79.3 years, and $66 \%$ of patients reported one or more comorbidities. The most frequent cause of injury was fall and zygomatic fractures were the most frequently observed injuries. Falls were associated with a low FISS value $(p<.005)$. Concomitant injuries were observed in $27.3 \%$ of patients. Falls were associated with the absence of concomitant injuries. The ninth decade $(p<.05)$ and a high FISS score $(p<.005)$ were associated with concomitant body injuries too.

Conclusions: This study confirms the role of falls in the epidemiology of facial trauma in the elderly, but also highlights the frequency of involvement of females, and the high frequency of zygomatic fractures. 
Keywords: facial fractures; multicenter; epidemiology; etiology; falls.

\section{INTRODUCTION}

The progressive aging of European population seems to determine a change in the epidemiology, incidence and etiology of maxillofacial fractures. ${ }^{1-22}$ Young adults, as they are physically and socially active, have a greater risk of being injured in motor vehicle accidents, assaults, and sports activities, whereas facial trauma in elderly patients is commonly associated to age-related changes and systemic pathologic conditions. ${ }^{5}$ However, increasing longevity, more active lifestyles, and a growth in the ratio of the elderly in the population involve an increase in the frequency of old patients sustaining craniofacial trauma, as well as management and treatment of maxillofacial trauma in the elderly population. ${ }^{6-8}$

Therefore, a thorough understanding of the epidemiology and patterns of maxillofacial fractures in the elderly population is essential for a more appropriate management of these patients and to develop more effective treatment strategies and possibly prevent injuries. ${ }^{5-6}$

Previous publications focusing on geriatric facial fractures are limited. The relative infrequency of facial fractures in the elderly population and the rarity of their surgical treatment in the past was probably the reason why this topic did not attract great attention in the literature. ${ }^{9}$ However, the progressive ageing of population in developed countries suggests that these injuries should receive more attention. ${ }^{9}$

Therefore, several European centers that had already shown research experience in maxillofacial trauma decided to collaborate on a multicenter research project about maxillofacial fracture epidemiology and management in the elderly patients.

The objective of the present study was to assess the demographic variables, causes, and patterns of facial fractures in elderly population (with 70 years or more) managed at several European departments of oral and maxillofacial surgery. The results of this multicenter collaboration evaluating maxillofacial trauma epidemiology in the elderly population over a 5-year period are presented.

\section{MATERIALS AND METHODS}

This study was conducted at several European departments of oral and maxillofacial surgery: Division of Maxillofacial Surgery, University of Eastern Piedmont (Novara, Italy); Department of Maxillofacial Surgery, University Hospital Dubrava (Zagreb, Croatia); Clinic of Maxillofacial Surgery, School of Dentistry, University of Belgrade (Belgrade, Serbia); Department of Oral surgery, Faculty of Dental medicine, Medical University (Plovdiv, Bulgaria); Department for Oral and Maxillofacial 
Surgery, Bogomolets National Medical University (Kiev, Ukraine); Service de Stomatologie et Chirurgie Maxillo-faciale, CHU de Nantes (Nantes, France); Department of Oral and Maxillofacial Surgery, Aalborg University Hospital (Aalborg, Denmark); Department of Maxillofacial Surgery, North Estonia Medical Centre Foundation (Tallinn, Estonia); Department of Oral and Maxillofacial Surgery, Helsinki University Hospital (Helsinki, Finland); Oral and Maxillofacial Surgery - Hospital Dentistry Unit, University Hospital of Besançon (Besançon Cedex, France); Department of Maxillofacial and Oral Surgery of the University Medical Centre (Ljubljana, Slovenia); Maxillofacial Department, Hospital Universitario Central de Asturias (Oviedo, Spain).

This study is based on a systematic computer-assisted database that allowed the recording of data from all geriatric patients (70 years or more) with facial fractures from the involved maxillofacial surgical units across Europe between January 1, 2013, and December 31, 2017.

Only patients with 70 years or more that were diagnosed with facial fractures were included. The following data were recorded for each patient: gender, age, voluptuary habits (drug-addiction, smoke or alcohol consumption), comorbidities, etiology, site of facial fractures, synchronous body injuries.

Facial Injury Severity Score according to Bagheri et al $^{10}$ was calculated for each patient too. The following categories of the cause of injury were considered: fall, motor vehicle accident, assault, sport injury, work injury, and other cause. Facial fractures were determined from computed tomography scans at admission to the hospital and classified as fractures of the mandible, orbital-zygomatic-maxillary complex (MZO), orbit, nose, Le Fort, frontal sinus, and nasoorbital-ethmoid (NOE) fracture. Orbital fractures were subclassified according to the involved walls. Fractures of the mandible were subclassified in fractures of the symphysis, parasymphysis, body, angle, ramus, coronoid, or condyle.

Patient characteristics were analyzed using descriptive statistics. Statistical analysis was used to search for associations among multiple variables. Statistical significance was determined using the $\mathrm{X} 2$ test or, if the sample sizes were too small, the Fisher exact test. Statistical significance was set at .05. We followed the Helsinki Declaration guidelines, according to local laws. The study was exempt from requiring institutional review board approval as a retrospective study, according to a local institution.

RESULTS 
A total of 1334 patients (599 male and 735 female patients) met the inclusion criteria and were included in the study. Of the patients, $45 \%$ were male patients whereas $55 \%$ were female patients, with a male-to-female ratio of 0.81:1.

In the different centers and countries the male to female ratio varied widely, with the highest value encountered in the Kyiv centre (Ukraine) study population (5.25:1) and the lowest value that was observed in Nantes (France) with an M:F ratio of 0.58:1. Table 1 and Figure 1 resumes the different male and female distribution among centers.

The mean age of the study population was 79.3 years (median, 78 years; standard deviation, 6.5 years; range, 70 to 100 years). According to decades, most patients ( 754 patients, $56 \%$ ) could be included in the seventh decade of age (70 - 79 years), in which males outnumbered females. In the eighth and ninth decades, the number of female patients was higher than men (Table 2, Figure 2). Statistical analysis confirmed the association of the seventh decade with male gender and the association of eighth and ninth decades with female gender, as shown in Table 2.

In the different centers, the observed values of mean age varied between the 76.9 years in Ljubljana (Slovenia) and the 81 years of Helsinki (Finland) and 85 years of Tallinn (Estonia) (Figure 3). Figure 4 shows that the distribution of patients according to decades of age was quite uniform among centers with values of patients belonging to the seventh decade ranging between about $50 \%$ and $70 \%$ in most centers. Nantes and Helsinki centers had the highest percentages of patients included in the eighth and ninth decades, whereas Kyiv, Ljubljana, and Belgrade centers had the lowest values.

Only 103 patients $(7,7 \%)$ out of 1334 reported one or more voluptuary habits, with 74 patients that reported alcohol drinking, as shown in Table 3.

On the whole, 881 patients (66\%) reported one or more comorbidities, the most frequent being hypertension (50\%), followed by diabetes (14\%), atrial fibrillation (9\%), heart ischemic disease (6\%), dementia (5\%), Alzheimer disease (4\%) (Figure 5).

As for etiology, the most frequent cause of injury was fall with 1054 patients (79\%), followed by MVA (105 patients, 8\%), assaults (55 patients, 4\%) (Figure 6). Table 4 and Figure 7 resume the etiology of facial trauma according to the decades of age, with the percentage of falls rising across the decades.

MZO fractures were the most frequently observed injuries with 515 fractures, followed by mandibular fractures (414 fractures), orbital fractures (373), Le Fort fractures (174), nasal fractures (165), and frontal sinus fractures (30) (Figure 8). Table 5 and Figure 9 show the different 
distribution of fractures according to genders: males outnumbered females as for frontal sinus, NOE, palatal, and Le Fort fractures. However, as for fracture type, no statistically significant difference between male and female patients was found ( $p>.05)$.

As for the mandible, 208 condylar fractures were observed, representing the most commonly observed mandibular fracture accounting for the $50 \%$. These were followed by body fractures and angle fractures (Figure 10). Instead, among orbital fractures, orbital floor fractures were the most frequently observed (74\%) (Figure 11).

The distribution of fractures across decades of age was quite uniform as depicted in Figure 12, with the only exceptions being represented by frontal sinus, NOE, and palatal fractures that were absent in the ninth decade.

The FISS mean score of the whole study population was 1.88 (median, 1; standard deviation, 1.59; range, 1 to 14).

The FISS mean score in the study populations as for etiology ranged between 1.71 following falls and 3.3 following work accidents (Figure 13). Falls were associated with a low FISS value $(p<.005)$. Table 6 shows that no statistically significant differences were calculated as for FISS values according to decades of age, gender, and comorbidities.

Concomitant injuries were observed in 364 patients out of 1334 (27.3\%). Most frequently observed concomitant injuries were orthopedic injuries (172 patients), followed by encephalic (155), thoracic (48), ocular (44), spine (31), and abdominal injuries (7). Table 7 shows the relationship between the presence of concomitant traumatic body injuries and the etiology, the age, as well as the FISS value: falls were associated with the absence of concomitant injuries $(p<$ .00005), whereas MVAs and assaults were associated with concomitant traumatic body injuries ( $p$ $<.00005$ and $p<.005$, respectively). Furthermore, the ninth decade $(p<.05)$ and a high FISS score $(p<.005)$ were associated with concomitant body injuries too.

\section{DISCUSSION}

Maxillofacial fractures in the elderly population have been increasing in recent years. ${ }^{5}$ Therefore, a methodical knowledge of the etiological mechanisms, as well as the complexity of clinical general conditions of older traumatized patients is crucial for the planning and execution of an appropriate treatment and management including the assessment of the medical status, which is a primary goal of preoperative preparation of elderly patients with fractures in the facial skeleton. ${ }^{6-7}$ 
The management of facial trauma in the elderly population requires selected adjustments in the algorithms commonly applied to the care of trauma victims. ${ }^{6}$ In fact, careful attention to preinjury comorbidities, nutrition, reduced cardiac and respiratory reserves is fundamental for the surgeon, as well as the implications on patient care. In fact, despite principles of facial trauma repair are also applicable in the elderly patients, their unique physiological status, medical history, and altered healing potential should suggest trauma teams to contemplate special considerations in selected cases and eventually modify standard treatment protocols. ${ }^{6-8}$ In gravely ill patients, the withholding of surgical treatment of facial fractures might also be considered when the delay or omission of care will not result in substantial function loss and will allow an acceptable (or at least a not important decrease of) quality of life.

To our knowledge, this is the first international multicenter study regarding maxillofacial trauma in the elderly population. The first part of the multicenter research project regarding facial trauma in geriatric patients focused on epidemiological features of such injuries.

The results of the present study highlighted that within a geriatric trauma population females outnumbered male patients with a male-to-female ratio of $0.81: 1$. Of course, differences in male to female ratio were observed across the different centers: for example, in Kyiv, Belgrade and Tallinn most patients were male, whereas a higher percentage of women were found in Aalborg, Besancon, Helsinki, Nantes and Oviedo.

The mean age of the whole study population was 79.3 years. As expected, according to decades, most patients $(56 \%)$ could be included in the seventh decade of age ( $70-79$ years), in which males outnumbered females. Instead, while the age increased, in the eighth and ninth decades, the number of female patients was progressively higher and higher than men. Statistical analysis confirmed the association of the seventh decade with male gender and the association of eighth and ninth decades with female gender. In the different centers, the observed values of mean age were quite uniform with most population ranging between 76.9 years (Ljubljana, Slovenia) and 81 years of mean age (Helsinki, Finland). Furthermore, the distribution of patients according to decades of age was quite uniform among centers with values of patients belonging to the seventh decade ranging between about $50 \%$ and $70 \%$ in most centers.

The results of the present study regarding age and gender distribution seem to give some important although expected indications: above 70 years of age, facial trauma are progressively more and more frequent in women than in men. This can be explained by a longer life expectancy in women in most European countries, in which, according to statistical demographics, in the 
period 2001 to 2016 the number of elderly people in the European Union rose overall by 26.6\%, while the overall population increased, during the same period, by $4.5 \%$. A further element of discussion is represented by the definition of "geriatric population" or "elderly patient". We decided to choose 70 years as a boundary. The World Health Organization (WHO) still consider 60 years as the starting age of "elderly", but, as it states, "although there are commonly used definitions of old age, there is no general agreement on the age at which a person becomes old". The WHO acknowledge that most developed world countries have accepted the chronological age of 65 years as a definition of 'elderly' or older person as it is many times associated with the age at which one can begin to receive pension benefits. However, the Joint Committee of Japan Gerontological Society and the Japan Geriatrics Society recently suggested a new classification in which old age would include people aged over 75 years. ${ }^{6-9}$ Therefore, in developed countries the starting age for a definition of the "elderly" seems to be progressively increasing together with the increase of quality if life and life expectancy. ${ }^{5}$ In conclusion, it is difficult to compare the few articles about maxillofacial trauma in older patients, as different definition of the elderly was used, but on the other hand it did not seem appropriate any more to include among the "geriatric population" people with 60-65 years.

Only $7,7 \%$ of patients reported one or more voluptuary habits, with 74 patients that reported regular alcohol drinking.

Drugs and alcohol misuse are recognized risk factors for MVA and interpersonal violence, as well as for maxillofacial trauma recidivism. The low percentage of alcohol drinking and drugs assumption within the elderly study population may be easily due to the high age, in comparison with the much higher percentage of voluptuary habits in young patients. ${ }^{11}$

As aforementioned, comorbidities probably represent one of the most important features to be considered for the management of the elderly patients with facial trauma. In our study population, the $66 \%$ of patients reported one or more comorbidities: hypertension, diabetes, atrial fibrillation, and heart ischemic disease were the most frequent medical illnesses, but neurological disorders such as dementia, Alzheimer disease, and Parkinson disease were not absolutely neglectable. Of course, the encountered widespread diffusion of cardiovascular conditions in elderly patients (hypertension, atrial fibrillation, and atrial ischemic disease) was often associated with the use of antithrombotic drugs, which need to be take into account before surgery. In fact, the presence of several comorbidities may determine the need for cardiologist consultations and/or further examinations before surgery. 
As for etiology, the most frequent cause of injury was fall with 1054 patients (79\%). This data confirmed the literature about this topic, as expected. Other causes of facial trauma in the elderly were more underrepresented, for example MVA (8\%) and assaults (4\%). The importance of falls as etiological factors is depicted by Figure 7: the percentage of falls rose across the decades. The increase of comorbidities across life may be responsible for the higher and higher frequency of falls, both for cardiovascular conditions or for neurological disorders. On the other hand, above 80 years, MVAs and work-related and sport-related injuries are expected to decrease due to the less active lifestyle of the oldest population.

As for fractures, MZO fractures were the most frequently observed injuries with 515 fractures, followed by mandibular fractures (414 fractures), orbital fractures (373), Le Fort fractures (174), nasal fractures (165), and frontal sinus fractures (30).

Gross calculations showed that males outnumbered females as for frontal sinus, NOE, palatal, and Le Fort fractures, whereas in women orbital fractures were more frequent, in agreement with the literature. However no statistically significant difference between male and female patients was found as for fracture type.

Condylar fractures represented the most commonly observed mandibular fracture accounting for the $50 \%$. The distribution of fractures across decades of age was quite uniform, with the only exceptions being represented by frontal sinus, NOE, and palatal fractures that were absent in the ninth decade.

A comparison with the epidemiology of facial trauma in young and adult population in the recent literature highlights zygomatic fractures seem to be over represented in the elderly population, whereas when a mandibular fracture has been diagnosed most fractures were condylar fractures. This may peculiar distribution of fractures may be due to two factors. On one hand, fall as etiological factor may frequently be responsible for zygomatic fractures, on the other hand the progressive atrophy of the mandibular bone (especially in edentulous patients) that is associated with the progressive ageing may have a role in the increase of incidence of condylar and body fracture in comparison with younger population.

The FISS mean score of the whole study population was 1.88. Fall - related injuries had the lowest mean FISS score with 1.71 points, whereas work - related accidents had the highest score (3.3) followed by assaults. No statistically significant differences were calculated as for FISS values according to decades of age, gender, and comorbidities. Instead, falls were associated with a low FISS value $(p<.005)$ 
Concomitant injuries were observed in $27.3 \%$ of patients. Falls were associated with the absence of concomitant injuries $(p<.00005)$, whereas MVAs and assaults were associated with concomitant traumatic body injuries $(p<.00005$ and $p<.005$, respectively). Furthermore, the ninth decade $(p<.05)$ and a high FISS score $(p<.005)$ were associated with concomitant body injuries too.

Therefore, the results of this epidemiological study seem to suggest that facial trauma in the geriatric population has some specific characteristics: above 70 years of age facial trauma is progressively more and more frequent in women than in men, probably due to a longer life expectancy in women in most European countries; comorbidities are frequently observed and they cannot be underestimated (especially in the elderly); the great majority of facial fractures are due to falls with percentages that continue to rise across the years, probably due to a less active lifestyle in the eighth and ninth decades; MZO fractures represent the most common facial fractures in the elderly; falls are statistically associated with a low FISS value and with the absence of concomitant injuries; the presence of concomitant traumatic body injuries is statistically associated with MVAs or assaults and with a higher FISS score.

Therefore, these last conclusions seem to identify two more frequent possible clinical scenarios that surgeons have to face when they are approaching a senior patient with facial trauma. The first scenario can be represented by a patient that reports a single or however few facial fractures (with a low FISS) probably due to a low-energy mechanism such as a fall, with few concomitant injuries.

The second scenario may foresee a senior patient that, following a high-energy mechanism (MVA or assault), reports multiple facial fractures (high FISS) in association with concomitant body injuries, such as orthopedic, thoracic, or encephalic lesions, that may need a really complex multidisciplinary management of the patient, especially if important pre-existing comorbidities are associated too.

\section{CONCLUSIONS}

In conclusion, the present study confirms the importance of up-to-date multicenter epidemiological data. Facial trauma in the geriatric population represents a field of research that can probably acquire more and more importance in the next years, together with the progressive ageing of the population in developed countries. This study confirms the role of falls in the epidemiology of facial trauma in the elderly, but also highlights the frequency of involvement of females, the high frequency of MZO fractures, and the possible identification of two more 
common clinical scenarios. The results of the present study suggest the need to create an expertise and multidisciplinary teams for the management of facial trauma in the elderly, given the possible high complexity if its management in high-energy accidents.

\section{REFERENCES}

1. Brucoli M, Boffano P, Pezzana A, Benech A, Corre P, Bertin H, Pechalova P, Pavlov N, Petrov P, Tamme T, Kopchak A, Romanova A, Shuminsky E, Dediol E, Tarle M, Konstantinovic VS, Jelovac D, Karagozoglu KH, Forouzanfar T. The "European Mandibular Angle" research project: the analysis of complications after unilateral angle fractures. Oral Surg Oral Med Oral Pathol Oral Radiol. 2019 Feb 28. pii: S2212-4403(19)30160-9. doi:

10.1016/j.00oo.2019.02.027. [Epub ahead of print]

2. Brucoli M, Boffano P, Broccardo E, Benech A, Corre P, Bertin H, Pechalova P, Pavlov N, Petrov P, Tamme T, Kopchak A, Hresko A, Shuminsky E, Dediol E, Tarle M, Konstantinovic VS, Petrovic M, Holmes S, Karagozoglu KH, Forouzanfar T. The "European zygomatic fracture" research project: The epidemiological results from a multicenter European collaboration. J Craniomaxillofac Surg. 2019 Apr;47(4):616-621.

3. Brucoli $M$, Boffano P, Pezzana A, Benech A, Corre P, Bertin H, Pechalova P, Pavlov N, Petrov P, Tamme T, Kopchak A, Romanova A, Shuminsky E, Dediol E, Tarle M, Konstantinovic VS, Jelovac D, Karagozoglu KH, Forouzanfar T. The "European Mandibular Angle" Research Project: The Epidemiologic Results From a Multicenter European Collaboration. J Oral Maxillofac Surg. 2019 Apr;77(4):791.e1-791.e7.

4. Boffano P, Kommers SC, Karagozoglu KH, Forouzanfar T. Aetiology of maxillofacial fractures: a review of published studies during the last 30 years. Br J Oral Maxillofac Surg. 2014 Dec;52(10):901-6.

5. Yamamoto K, Matsusue Y, Murakami K, Horita S, Sugiura T, Kirita T. Maxillofacial fractures in older patients. J Oral Maxillofac Surg. 2011 Aug;69(8):2204-10.

6. Marciani RD. Critical systemic and psychosocial considerations in management of trauma in the elderly. Oral Surg Oral Med Oral Pathol Oral Radiol Endod. 1999 Mar;87(3):272-80.

7. Atisha DM, Burr Tv, Allori AC, Puscas L, Erdmann D, Marcus JR. Facial Fractures in the Aging Population. Plast Reconstr Surg. 2016 Feb;137(2):587-93.

8. Shumate R, Portnof J, Amundson M, Dierks E, Batdorf R, Hardigan P. Recommendations for Care of Geriatric Maxillofacial Trauma Patients Following a Retrospective10Year Multicenter Review. J Oral Maxillofac Surg. 2018 Sep;76(9):1931-1936. 
9. Toivari M, Helenius M, Suominen AL, Lindqvist C, Thorén H. Etiology of facial fractures in elderly Finns during 2006-2007. Oral Surg Oral Med Oral Pathol Oral Radiol. 2014 Nov;118(5):539-45.

10. Bagheri SC, Dierks EJ, Kademani D, Holmgren E, Bell RB, Hommer L, Potter BE. Application of a facial injury severity scale in craniomaxillofacial trauma. J Oral Maxillofac Surg. 2006 Mar;64(3):408-14.

11. Foletti JM, Bruneau S, Farisse J, Thiery G, Chossegros C, Guyot L. Screening for psychiatric risk factors in a facial trauma patients. Validating a questionnaire. Rev Stomatol Chir Maxillofac Chir Orale. 2014 Dec;115(6):343-8

12. Brucoli M, Arcuri F, Giarda M, Benech A. Transient cardiac failure due to Takotsubo cardiomyopathy after surgical reduction of nasal fracture. J Craniofac Surg. 2011 Sep;22(5):1907-10.

13. Brucoli M, Boccafoschi F, Boffano P, Broccardo E, Benech A. The Anatomage Table and the placement of titanium mesh for the management of orbital floor fractures. Oral Surg Oral Med Oral Pathol Oral Radiol. 2018 Oct;126(4):317-321.

14. Boffano P, Benech R, Gallesio C, Arcuri F, Benech A. Current opinions on surgical treatment of fractures of the condylar head. Craniomaxillofac Trauma Reconstr. 2014 Jun;7(2):92-100.

15. Saponaro A, Stecco A, Brucoli M, Armienti F, Stellin L, Favano F, Benech A, Carriero A. Magnetic resonance imaging in the postsurgical evaluation of patients with mandibular condyle fractures treated using the transparotid approach: our experience. J Oral Maxillofac Surg. 2009 Sep;67(9):1815-20.

16. Brucoli M, Nestola DF, Baragiotta N, Boffano P, Benech A. Maxillofacial fractures: Epidemiological analysis of a single-center experience. Otorinolaringologia 2018; 68 (4): $132-137$

17. Giarda M, Tavolaccini A, Arcuri F, Brucoli M, Benech A. Surgical approach to isolated bilateral orbital floor fractures. Acta Otorhinolaryngol Ital. 2015 Oct;35(5):362-4.

18. Brucoli M, Boffano P, Magnano M, Mistretta R, Benech R, Benech A. The management of a high-risk patient with edentulous mandibular fractures. Otorinolaringologia 2019; 68: $42-44$

19. Brucoli M, Boffano $\mathrm{P}$, Bonaso $\mathrm{M}$, Benech $\mathrm{A}$. The management of a $\mathrm{Y}$-shaped fracture of the mandibular ramus. Otorinolaringologia 2019 September;69(3):192-5 
20. Ruslin M, Brucoli M, Boffano P, Forouzanfar T, Benech A. Maxillofacial fractures associated with sport injuries: a review of the current literature. Otorinolaringologia. 2019;69(3):16570.

21. Brucoli M, Boffano P, Baragiotta N, Pezzana A, Benech A. Chainsaw injuries of the maxillofacial region: our experience. Otorinolaringologia. Accepted, in Press.

22. Ruslin M, Brucoli M, Boffano P, Benech A, Wolff J, Dediol E, Uglešić V, Kovačič Z, Vesnaver A, Konstantinović V, Petrović M, Stephens J, Kanzaria A, Bhatti N, Holmes S, Pechalova P, Bakardjiev A, Malanchuk V, Kopchak A, Galteland P, Mjøen E, Skjelbred P, Bertin H, Corre P, Løes S, Lekven N, Laverick S, Gordon P, Tamme T, Akermann S, Karagozoglu K, Kommers S, de Visscher J, Forouzanfar T. Motor -vehicle accidents related maxillofacial injuries: a multicentre and prospective study. Oral Surg Oral Med Oral Pathol Oral Radiol. 2019 Sep;128(3):199-204.

\section{LEGENDS:}

Figure 1: Male (blue) and female (pink) distribution among centers.

Figure 2: Male (blue) and female (pink) distribution according to decades of age.

Figure 3: Mean age in the different centers.

Figure 4: Distribution of patients according to decades of age.

Figure 5: Comorbidities within the study population.

Figure 6: Etiology distribution within the study population.

Figure 7: Etiology of facial trauma according to decades of age.

Figure 8: Fracture distribution.

Figure 9: Distribution of fractures according to gender.

Figure 10: Mandibular fractures distribution.

Figure 11: Orbital fractures distribution.

Figure 12: Distribution of fractures across decades of age.

Figure 13: Mean FISS score according to etiology. 


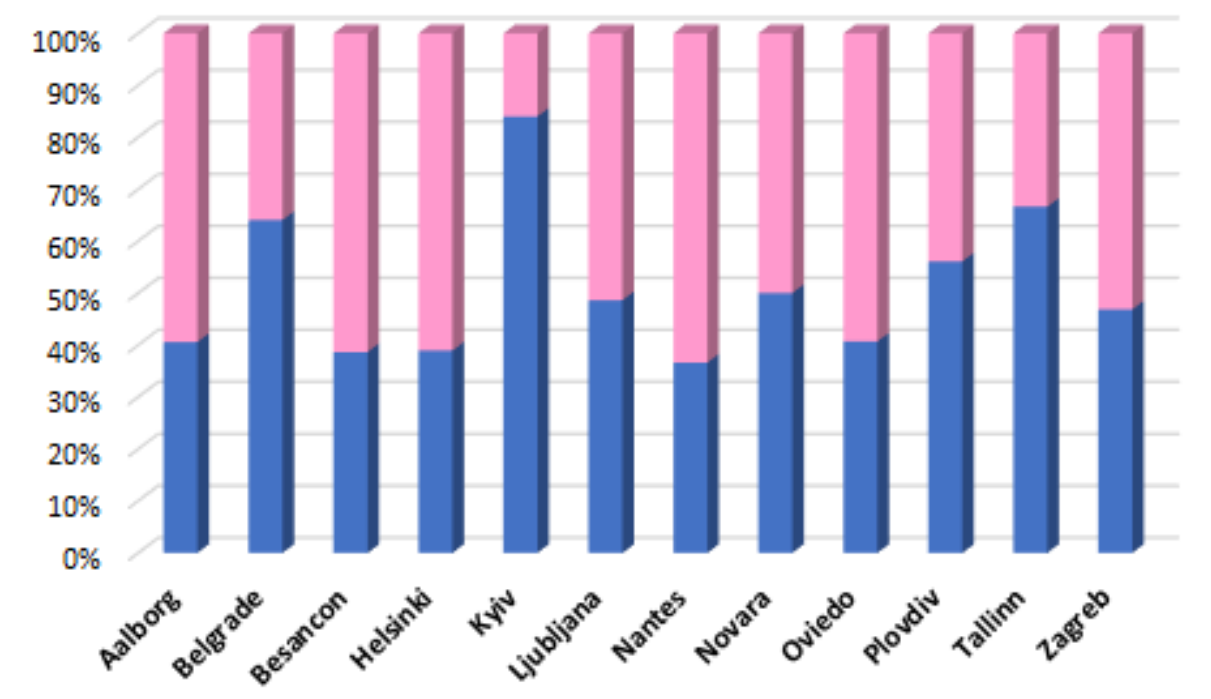

Figr-1 


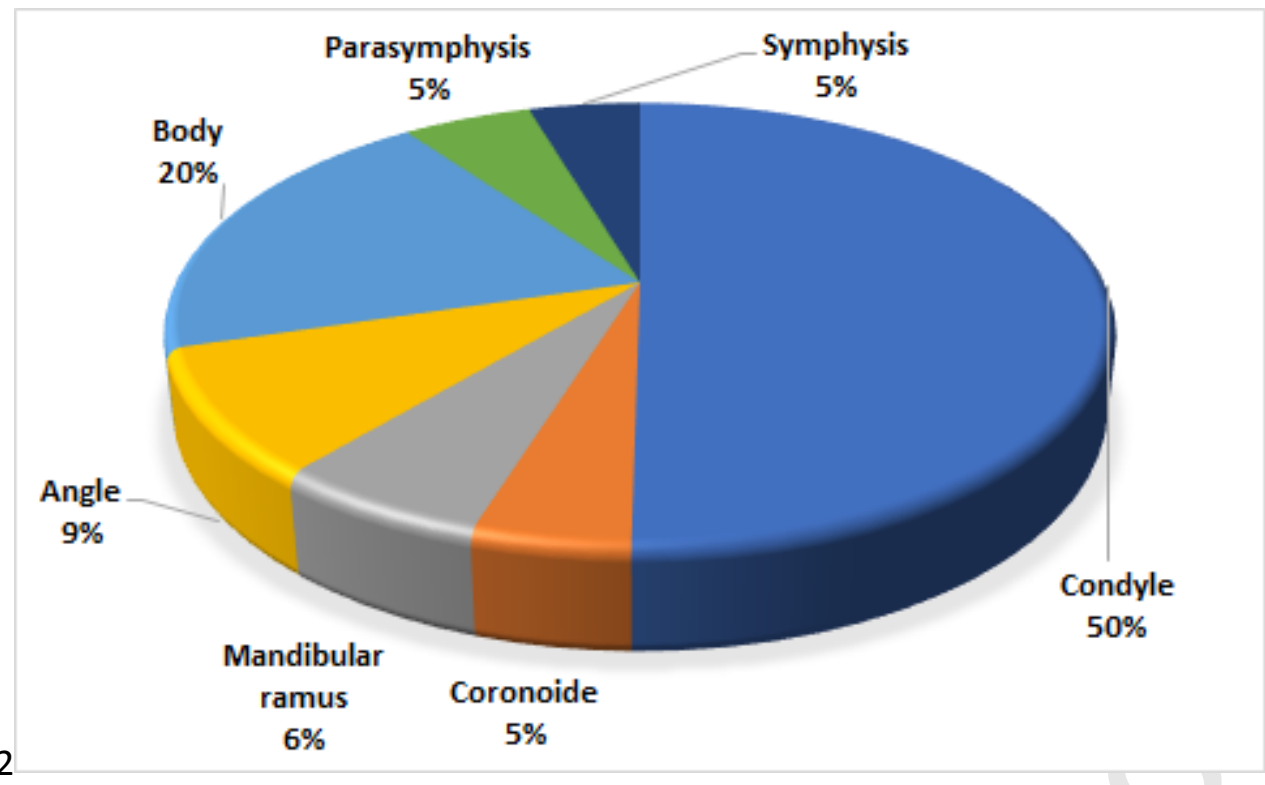

Figr-2 


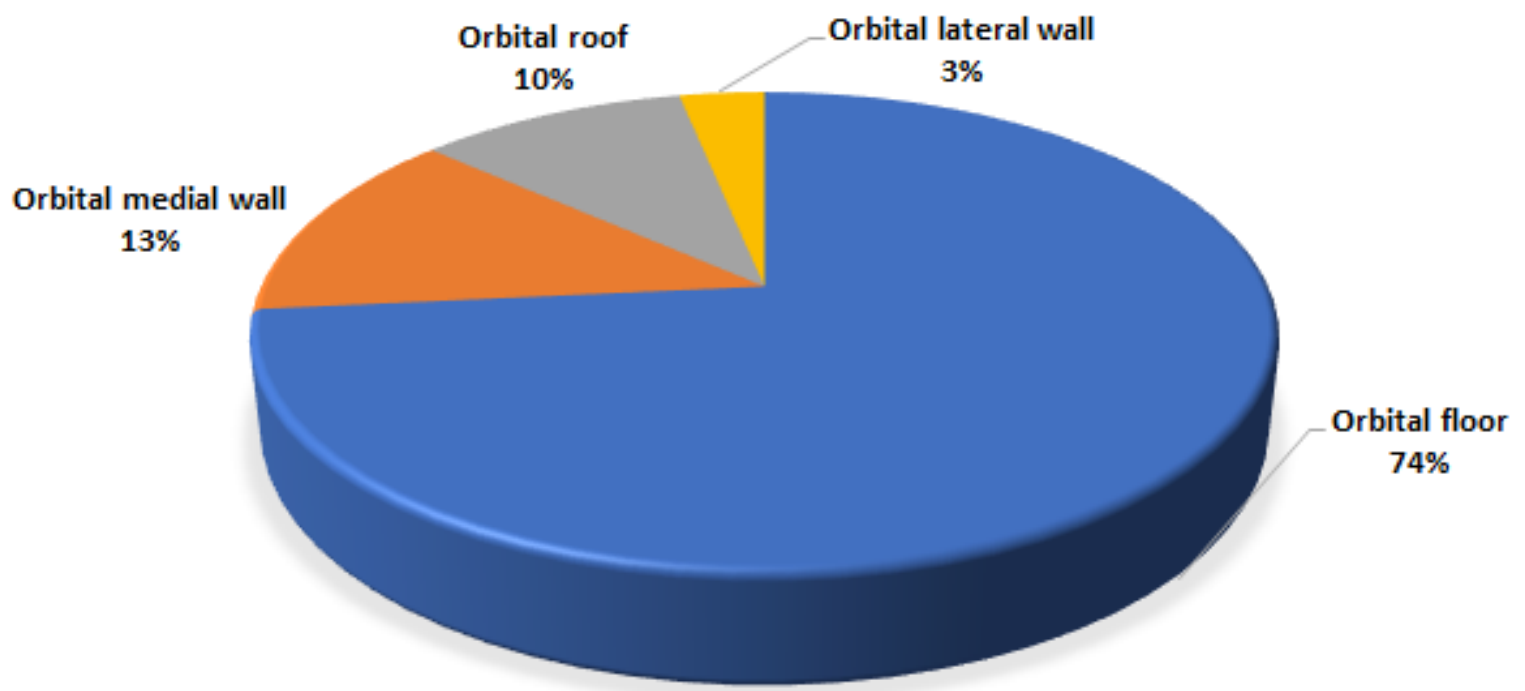

Figr-3 
Figr-4

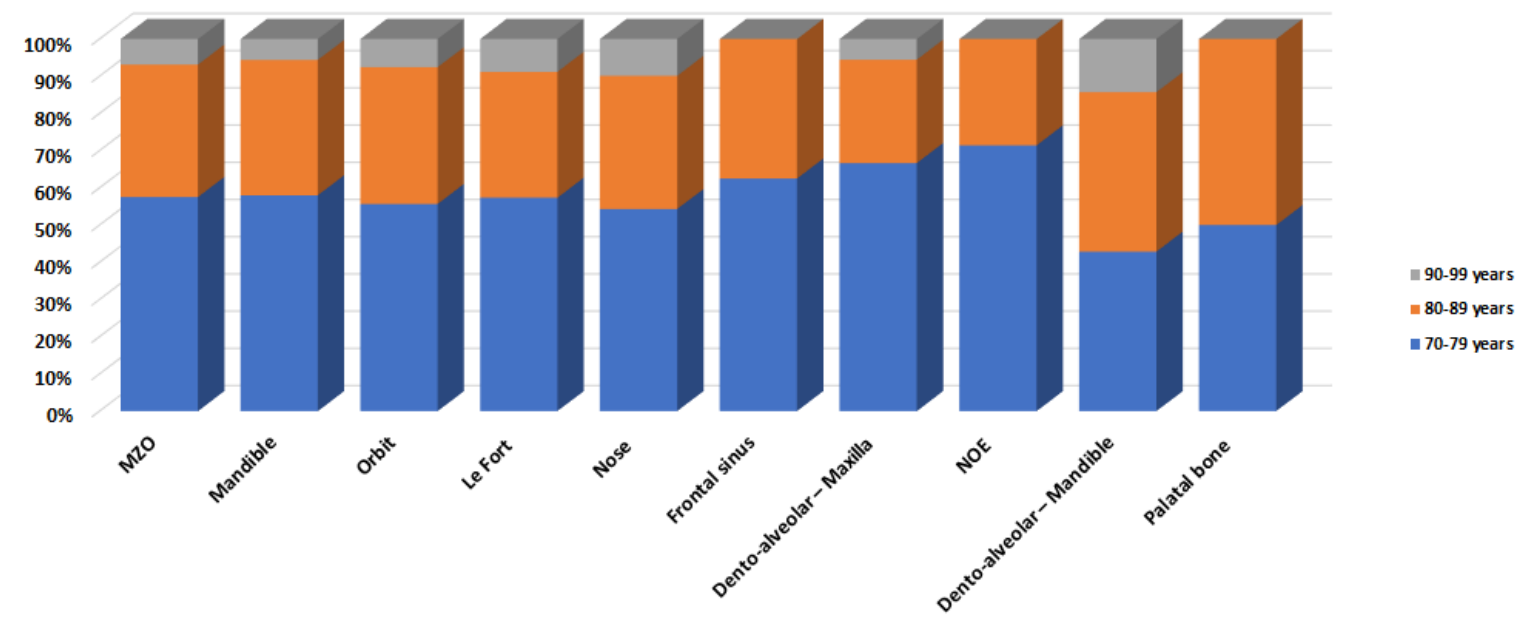

Page 17 of 33 


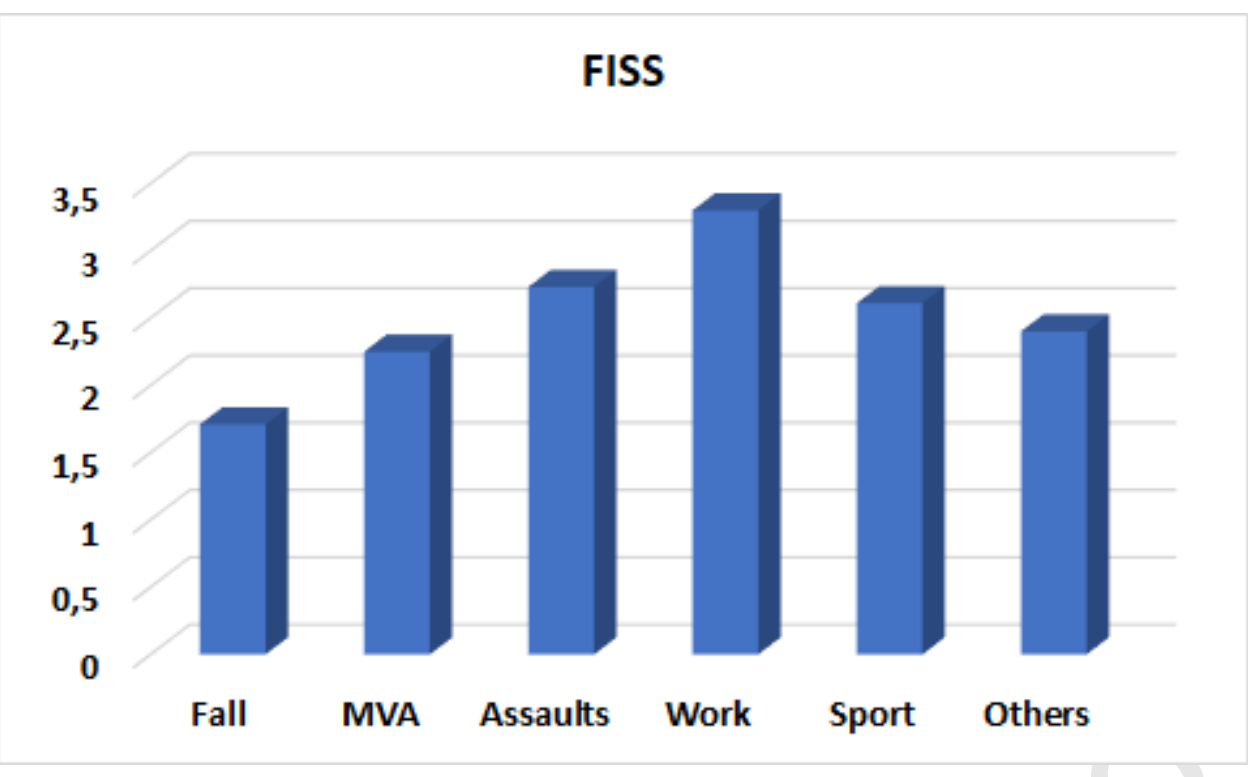

Figr-5 


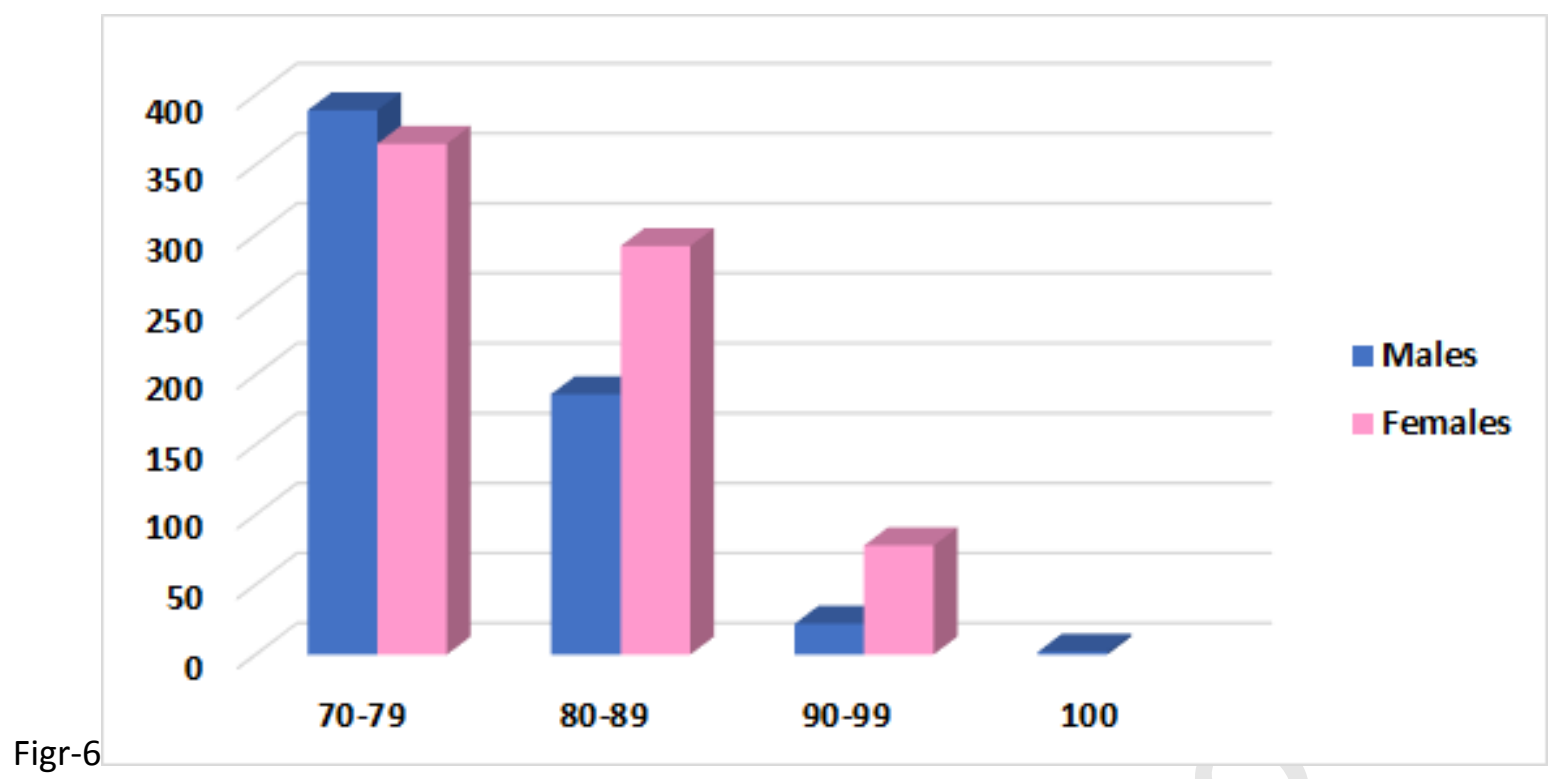

Page 19 of 33 


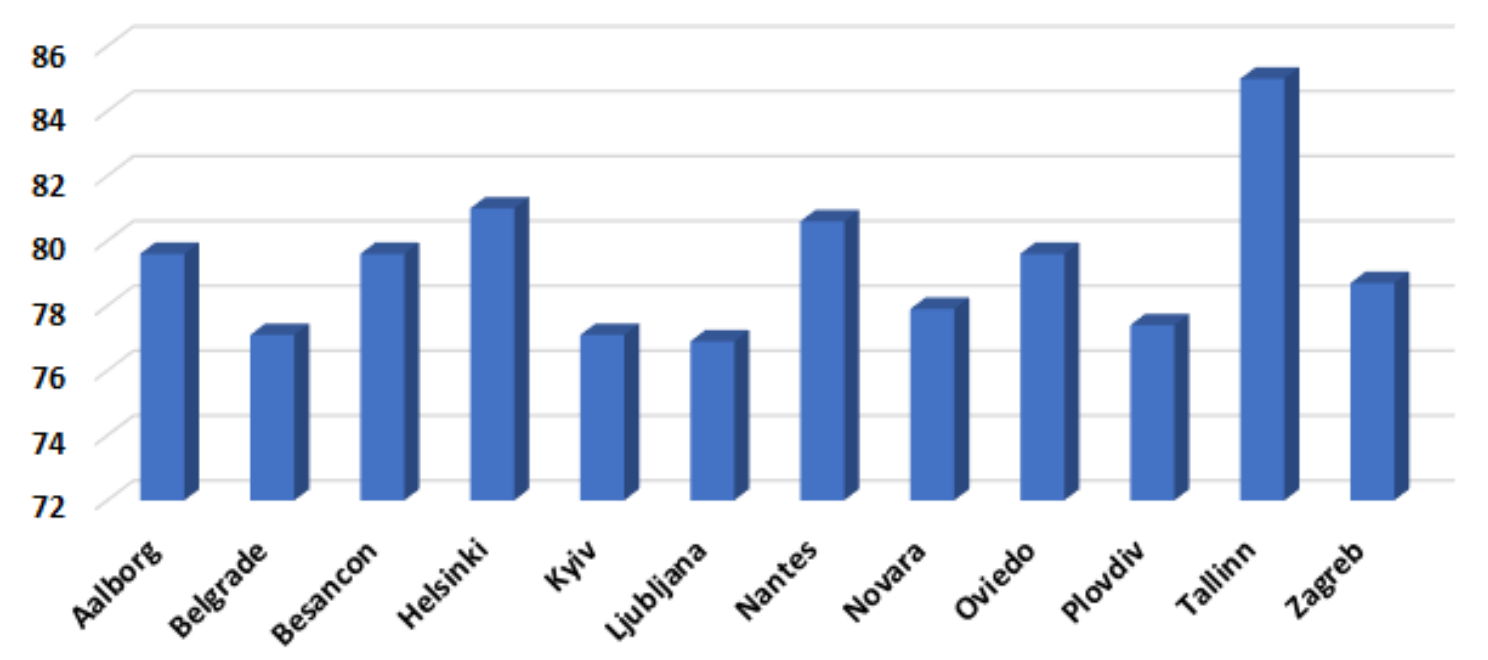

Figr-7 


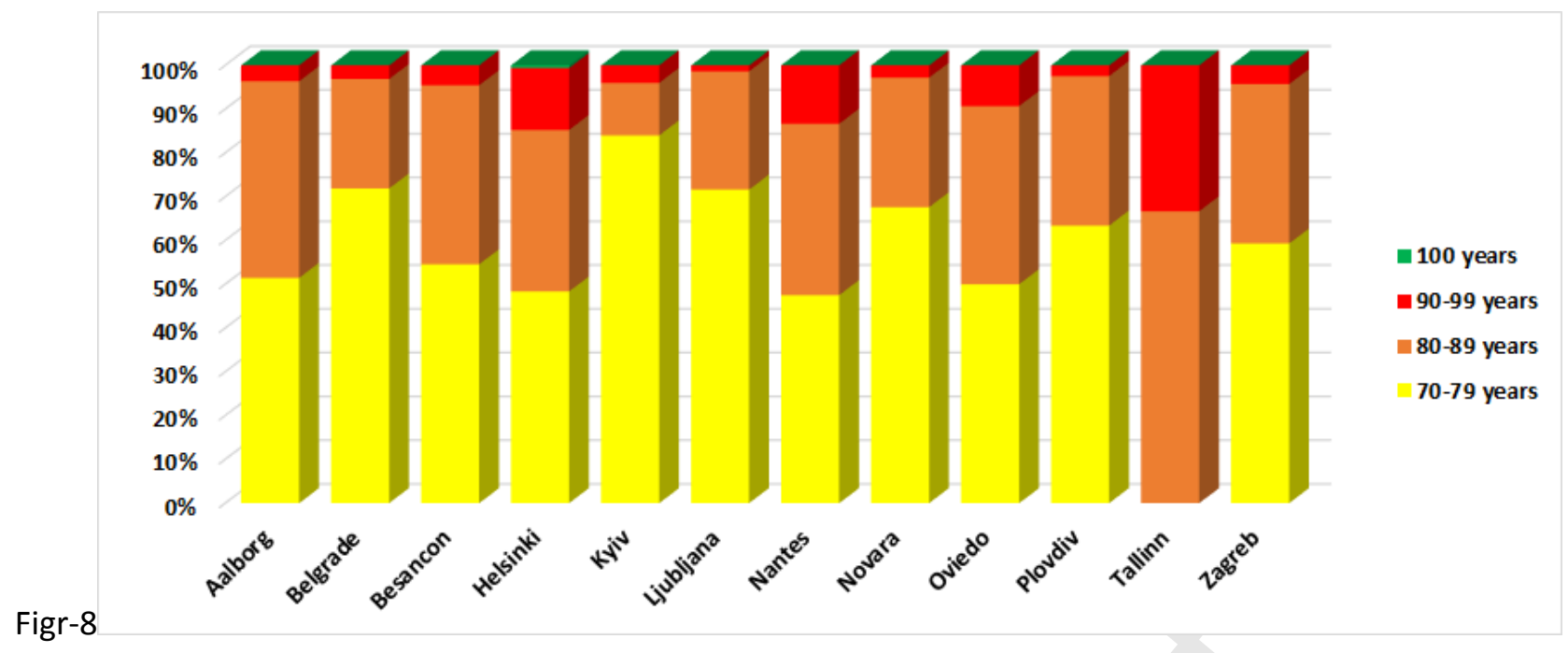

Page 21 of 33 


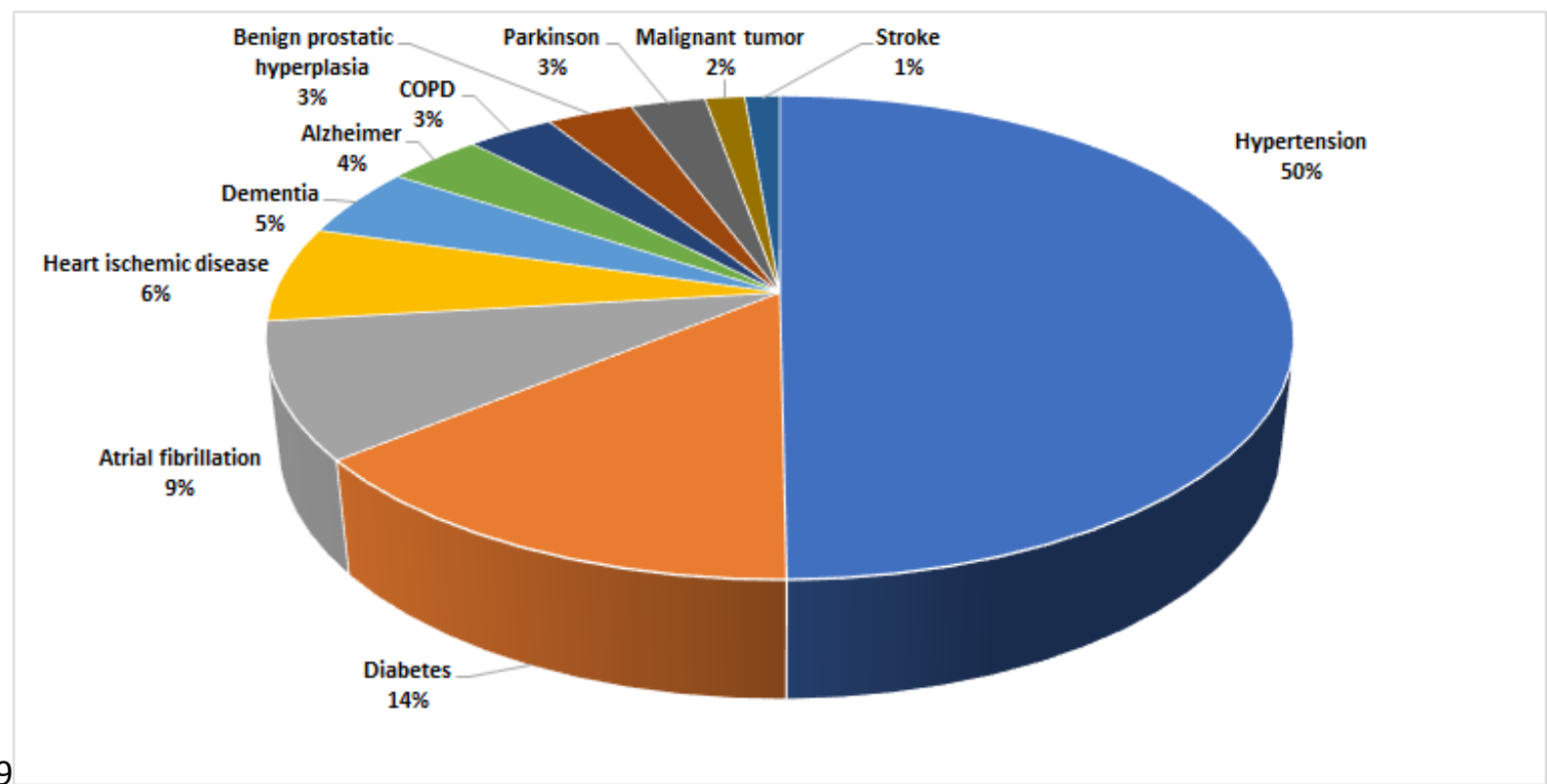

Figr-9 


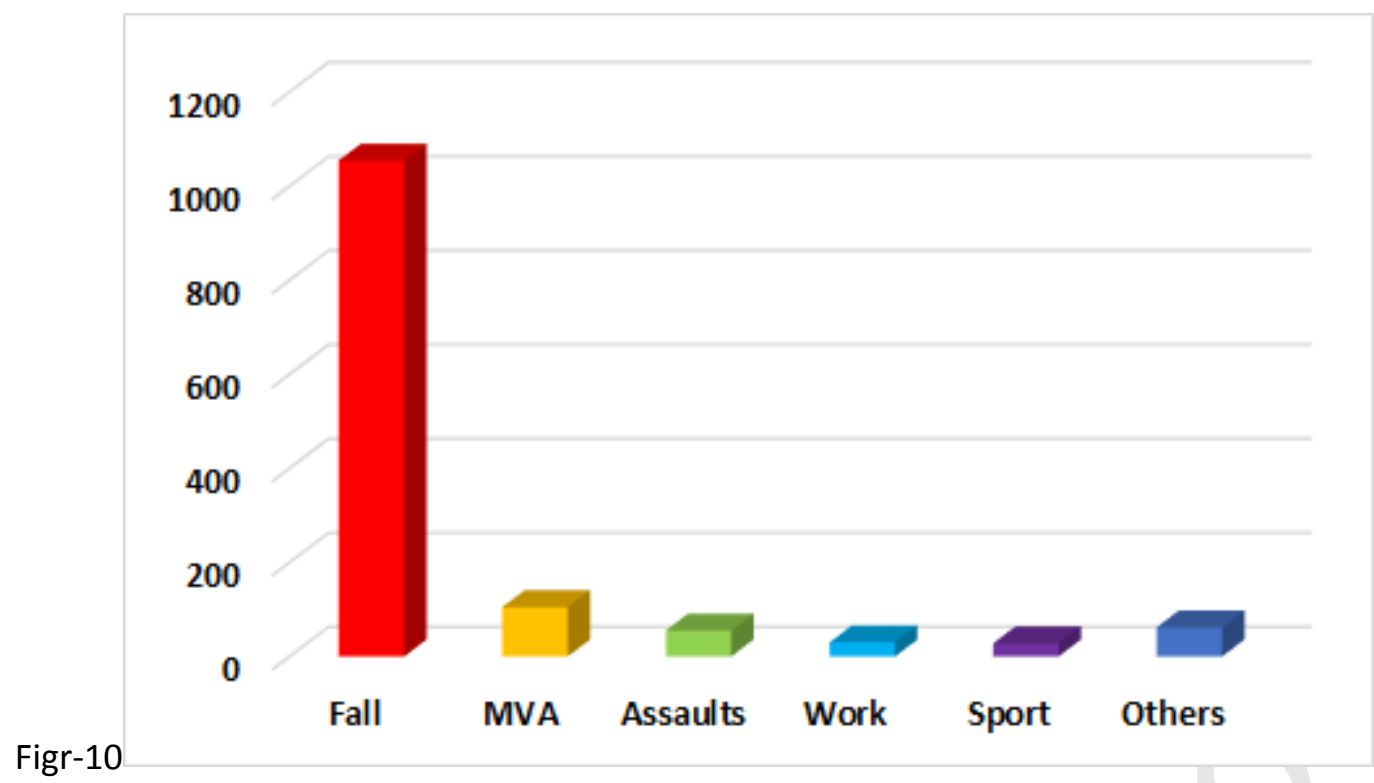

Page 23 of 33 
Figr-11

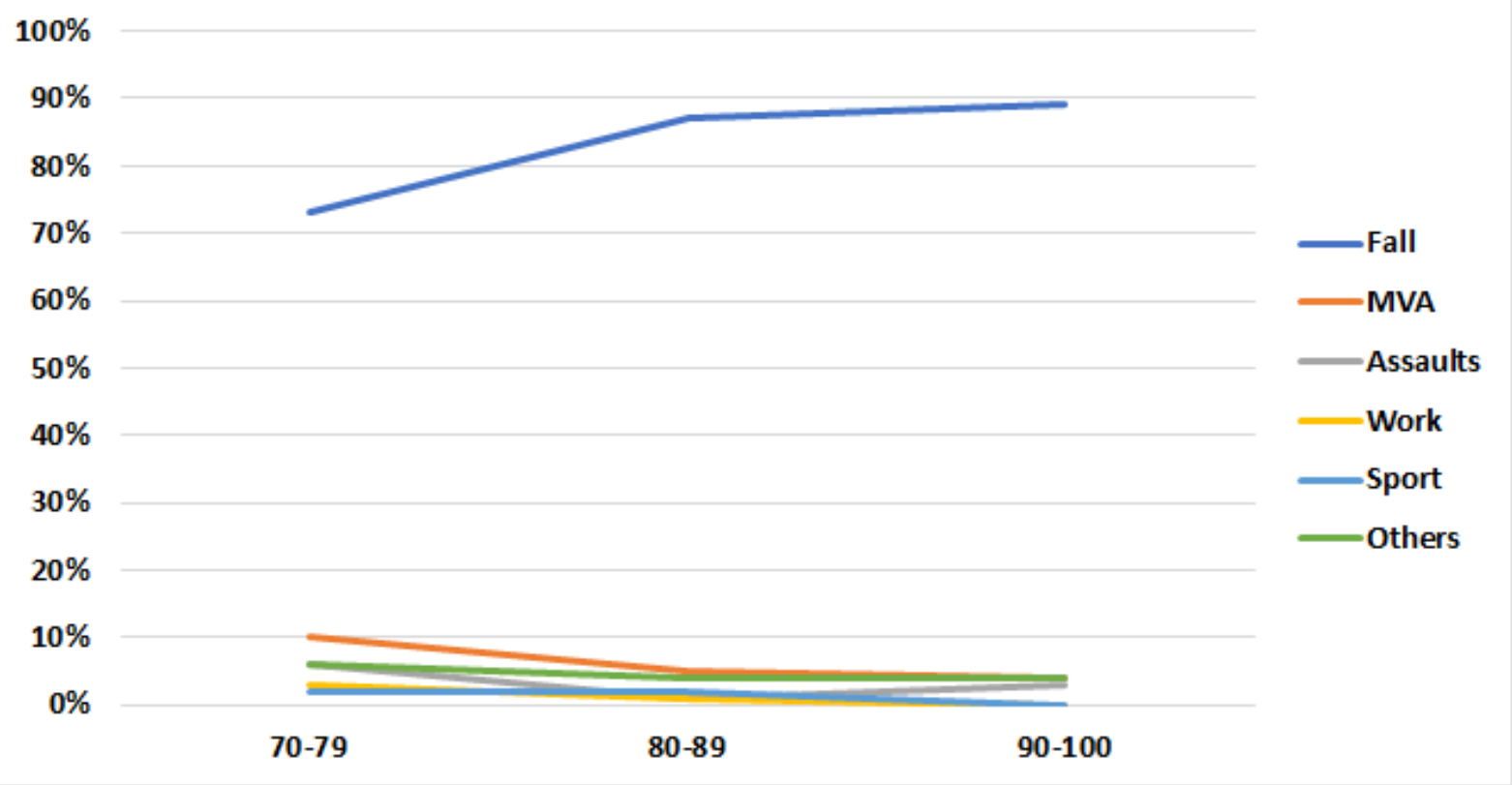


Figr-12

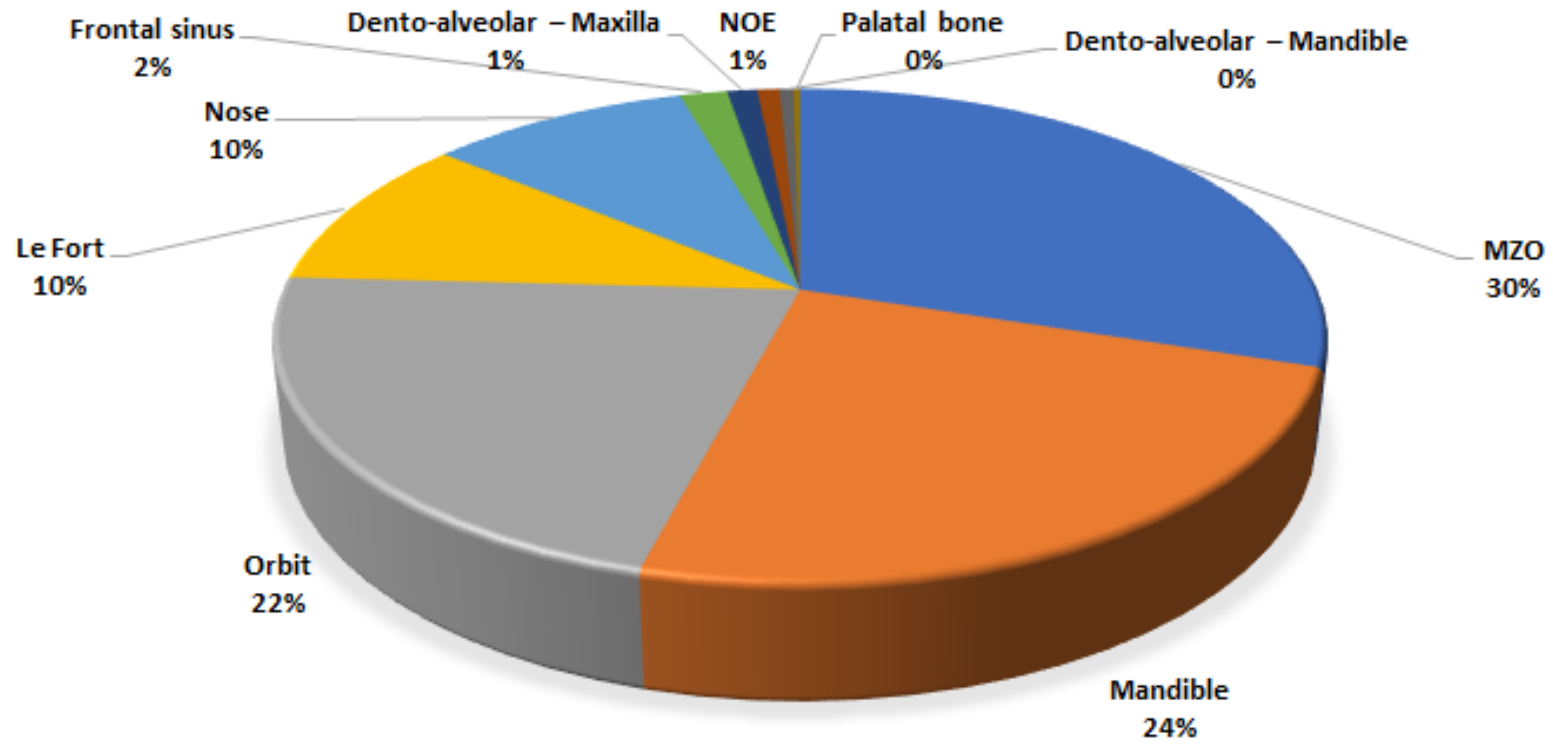

Page 25 of 33 
Figr-13

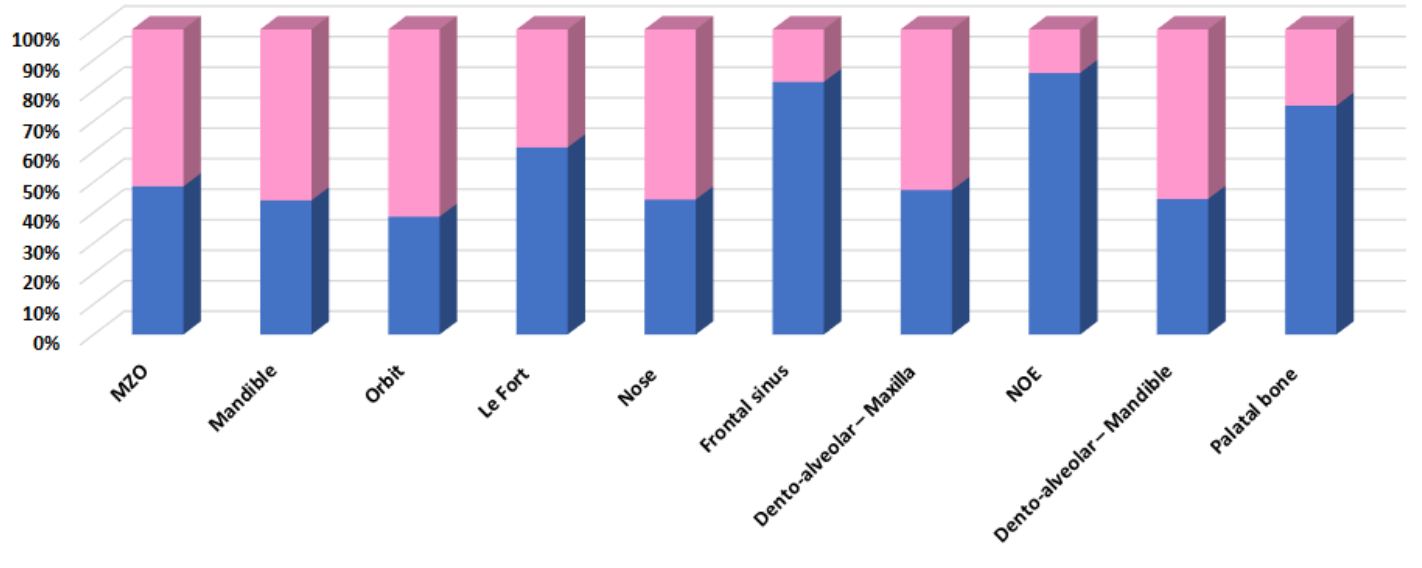

Males $\quad$ Females 
Table 1: Sex distribution in the European centers.

\begin{tabular}{|l|c|c|c|c|}
\hline & Total patients & M & F & M: F ratio \\
\hline Aalborg & 138 & 56 & 82 & $0,68: 1$ \\
\hline Belgrade & 64 & 41 & 23 & $1,78: 1$ \\
\hline Besancon & 44 & 17 & 27 & $0,64: 1$ \\
\hline Helsinki & 339 & 132 & 207 & $0,64: 1$ \\
\hline Kyiv & 25 & 21 & 4 & $5,25: 1$ \\
\hline Ljubljana & 74 & 36 & 38 & $0,95: 1$ \\
\hline Nantes & 120 & 44 & 76 & $0,58: 1$ \\
\hline Novara & 142 & 71 & 71 & $1: 1$ \\
\hline Oviedo & 86 & 35 & 51 & $0,69: 1$ \\
\hline Plovdiv & 41 & 23 & 18 & $1,28: 1$ \\
\hline Tallinn & 3 & 2 & 1 & $2: 1$ \\
\hline Zagreb & 258 & 121 & 137 & $0,88: 1$ \\
\hline & 1334 & 599 & 735 & $0,81: 1$ \\
\hline
\end{tabular}


Table 2: Gender distribution according to decades of age in the study population

\begin{tabular}{|c|c|c|c|c|}
\hline & \multicolumn{4}{|c|}{ Decades of age } \\
\hline & $\mathbf{7 0 - 7 9}$ years & $\mathbf{8 0 - 8 9}$ years & $\mathbf{9 0 - 9 9}$ years & $\mathbf{1 0 0}$ years \\
\hline Males & 389 & 186 & 22 & 2 \\
\hline Females & 365 & 292 & 78 & \\
\hline & $p<.0005$ & $p<.005$ & $p<.005$ & \\
\hline
\end{tabular}


Table 3: Voluptuary habits in the study population

\begin{tabular}{|l|c|c|c|c|}
\hline & \multicolumn{4}{|c|}{ Decades of age } \\
\hline & $\mathbf{7 0 - 7 9}$ years & $\mathbf{8 0 - 8 9}$ years & $\mathbf{9 0 - 9 9}$ years & Total \\
\hline alcohol & 61 & 13 & & 74 \\
\hline smoking & 11 & 5 & 1 & 17 \\
\hline alcohol + smoking & 10 & 1 & & 11 \\
\hline Alcohol + drug & 1 & & & 1 \\
\hline
\end{tabular}


Table 4: Etiology of facial trauma according to decades of age.

\begin{tabular}{|c|c|c|c|c|c|}
\hline & $\mathbf{N}$ total & $\%$ total & $\begin{array}{c}70-79 \\
\text { years }\end{array}$ & $\begin{array}{c}80-89 \\
\text { years }\end{array}$ & $\begin{array}{c}90-100 \\
\text { years }\end{array}$ \\
\hline Fall & 1054 & 79 & 548 & 415 & 91 \\
\hline MVA & 105 & 8 & 76 & 25 & 4 \\
\hline Assaults & 55 & 4 & 45 & 7 & 3 \\
\hline Work & 30 & 2 & 25 & 5 & 0 \\
\hline Sport & 28 & 2 & 18 & 10 & 0 \\
\hline Others & 62 & 5 & 42 & 16 & 4 \\
\hline Total & 1334 & 100 & 754 & 478 & 102 \\
\hline
\end{tabular}


Table 5: Fractures distribution within the study population

\begin{tabular}{|l|c|c|c|}
\hline & Total & Males & Females \\
\hline MZO & 515 & 250 & 265 \\
\hline Mandible & 414 & 182 & 232 \\
\hline Orbit & 373 & 144 & 229 \\
\hline Le Fort & 174 & 84 & 53 \\
\hline Nose & 165 & 73 & 92 \\
\hline Frontal sinus & 30 & 24 & 5 \\
\hline Dento-alveolar-Maxilla & 19 & 9 & 10 \\
\hline NOE & 14 & 12 & 2 \\
\hline Dento-alveolar - Mandible & 9 & 4 & 5 \\
\hline Palatal bone & 4 & 3 & 1 \\
\hline
\end{tabular}


Table 6: FISS score according to decades of age, gender, and comorbidities.

\begin{tabular}{|ll|l|l|}
\hline & & FISS & P \\
\hline Decades of age & $70-79$ years & 1,88 & $>.05$ \\
& $80-89$ years & 1,89 & \\
\hline Gender & $90-99$ years & 1,93 & \\
& Females & 1,65 & $>.05$ \\
\hline Comorbidities & Males & 2,18 & \\
& Yes & 1,89 & $>.05$ \\
\cline { 2 - 3 } & No & 1,88 & \\
\hline
\end{tabular}


Table 7: Concomitant injuries according to etiology, decades of age, and FISS score.

\begin{tabular}{|c|c|c|c|c|}
\hline & \multicolumn{2}{|c|}{ Concomitant injuries } & \multirow[b]{2}{*}{$\mathbf{P}$} \\
\hline & & Yes & No & \\
\hline \multirow[t]{3}{*}{ Decades of age } & $70-79$ years & 209 & 545 & NS \\
\hline & $80-89$ years & 116 & 362 & NS \\
\hline & $90-100$ years & 41 & 61 & $<.05$ \\
\hline \multirow[t]{6}{*}{ Etiology } & Fall & 251 & 803 & $<.00005$ \\
\hline & MVA & 50 & 55 & $<.00005$ \\
\hline & Assaults & 26 & 29 & $<.005$ \\
\hline & Work & 6 & 9 & NS \\
\hline & Sport & 11 & 32 & NS \\
\hline & Other & 20 & 42 & NS \\
\hline FISS score & & 1,78 & 2,15 & $>.05$ \\
\hline
\end{tabular}

NS: Not statistically significant $(p>.05)$ 